the telephones by a resistance. There is also a rejector circuit for tuning out near stations (acting as a wave filter). The valves are of the dull emitter type, with their filaments in series on the same battery that supplies the filaments of the two further power amplifier valves, the equipment for which is on the lower panel. A strength switch is here provided for the loud speaker, and a convenient switch for using one, two, three, or four valves at will and connecting or disconnecting the loud speaker by moving the knob in and out. This is so arranged that the head telephones cannot be connected to the higher numbers of valves, to avoid risk of damage. A set of this kind supplied to the
President of Poland is said to pick up in that country all the British broadcasting stations.

A certain amount of miscellaneous scientific apparatus is shown in the British Government Pavilion in sections organised by the National Physical Laboratory, the Royal Society, the Science Museum, South Kensington, and the Royal Institution. Those of electrical interest include some early types of incandescent lamps, historic apparatus used by Faraday, a collection of early Crookes' and X-ray tubes, mass spectrum apparatus of Dr. F. W. Aston, and Prof. C. G. Barkla's apparatus by which the polarisation of scattered $\mathrm{X}$-rays and characteristic X-rays were discovered.

\title{
Exhibition of the Royal Academy of Arts, I924.
}

\section{$\mathrm{T}$} $\mathrm{E}$ late Mr. Clutton Brock claimed with eloquent and reasoned insistence that, for its perfection, man's intellectual development needs to be duly tinged with æsthetics, the love of beauty for its own sake, as well as with philosophy, the science of conduct, on an equal footing with the love of truth; and his doctrine is supported by other apostles of the new Trinity of truth, goodness, and beauty. Assuming that a modicum of philosophy is the common heritage of them all, we may agree that the denizens of Burlington House have need of one another, and that the student of science is an imperfect creature unless he has a love of beauty for its own sake, which it is the first duty of the Royal Academy to expound and encourage. It is, indeed, not difficult to agree. Scientific discoveries differentiate themselves in ways other than the mere sum and substance of the improvement of natural knowledge. Some expositions of discovery are really beautiful, others are really not.

For good or ill, there is nothing on the scientific side that exactly corresponds with the annual exhibition of the Royal Academy. Artists are not exactly invited once a year to come and look, and then say what they think, from the point of view of beauty, of our exposition of science. There would be something worth saying if they were ; we might at least learn something about what illustrations ought to be and save thoughtful readers untold worries.

This year's academy comprises 674 paintings in oil, $\mathrm{I} 85$ in water colour, $\mathrm{I} 52$ miniature paintings, I4I drawings and engravings, 196 architectural drawings, and 215 sculptures - an extensive expression of the natural demand for the cultivation of the sense and power of beauty. And as one passes through the rooms and is faced with the question, "Well, what do you think of it all ?" one is tempted to speculate on the canons or motives which guide the artist's mind in the exercise of his function of being inspired by and in turn inspiring his environment.

Perhaps the most prominent motive is the aid to the memory of the beautiful, which, at the best, is changing and evanescent, and which the layman might never realise at all without the artist's aid. To judge by the pictures of the year the human "form divine " clothed in various ways is the most appealing feature of their environment for the artists of the twentieth century, sometimes recalling Solomon in all his glory and sometimes with nothing on.

The appeal is more on the biological and psycho- logical side than the physical. The studies of inanimate nature are less numerous and less striking than those of men and women, and animals, tame or wild. Even the portraits of the scientific bear out this suggestion. To set against those of Sir Donald MacAlister, Bt., of Tarbert (No. r87), by George Henry, R.A. ; Lieut.-Gen. Sir John Goodwin, K.C.B., F.R.C.S. (2I7), by Maurice Greiffenhagen, R.A.; Sir Charles Sherrington, G.B.E., P.R.S. (630), by Augustus E. John, A.R.A.; and Prof. A. C. Seward, F.R.S., Master of Downing College (632), by William O. Hutchison, there are, it is true, portraits of Sir J. J. Thomson, O.M., F.R.S. (34I), by René de I'Hôpital, and Sir Maurice Fitzmaurice, C.M.G., F.R.S. (305), for the Institution of Civil Engineers, by George Harcourt, A.R.A.; but they are two against four, and the Master of Trinity seems a little more "cornered" than one is accustomed to. To get a good view of the president of the Royal Society it is well to choose a bright day, otherwise the canon, ars est celare artem, may seem to have been rather roughly disregarded by Mr. John. The contrast of " art" between that and its near neighbour the Master of Downing is almost painful.

Passing from the variously adorned to the unadorned, bathing scenes are numerous and occasionally curious (22), and perhaps the student of biological statistics might find on investigation that the correlation between the absence of adornment and bobbed hair has actually changed its sign from the negative to the positive since Adam and Eve left the Garden of Eden, or even since Tennyson "waited for the train at Coventry."

Not many of the landscapes are very impressive. For a layman the best are those of Adrian Stokes, R.A., Cypress and Olive (I43), San Vigilio (212), A Ring of Cypresses (54); Sir D. Murray, R.A., pictures of Wells $(272,493,464)$, and those of the neighbourhood of London by Mr. W. L. Wyllie, R.A. (333 and 587 ), to which is added one like unto them, (I 7 I) Scarborough Castle. Artists apparently still insist on going to medieval painters instead of to Nature for their clouds, except Mr. E. L. Lawrenson $(16,26 \mathrm{r}, 627)$, who is adventurous but not quite happy with the colouring of his cloud-margins. There is a tendency among the landscapes to bury the scene in a murky atmosphere, not at all void, but without form. Mr. Wyllie finds the London atmosphere convenient for that, and Mr. Oliver Hall, A.R.A. (I24, 242), finds the same kind of dingy sky in Dorset and the Lake District. It will be rather unfortunate if the artists make the murky atmosphere of cities a fashionable form

$$
\text { NO. } 2848 \text {, vOL. I I } 3]
$$


of beauty. A curious form of protest against such a misadventure is to be found in 598 , in which $\mathrm{Mr}$. George $\mathrm{H}$. Day uses the smoke of a channel steamer as a background for most brilliant coloured dresses ; but that is compensated on the other side by 674 , Isabel Codrington, in which cultivation of dirtiness as a fine art is pressed as far as it will go, and a little farther.

Of the motive to discern beauty which the layman would never think of there is not much evidence, unless we include idealised forms or surroundings such as the sculpture of an angel for a memorial (136r), Charles Wheeler, or (33), Angela Gibbons, for the decoration of a church. In their idealised unreality they make the student whose first aim is truth wonder about art as the handmaid of religion, whether, after all, the Second Commandment has not a claim for serious consideration.
Incidentally one may learn from the exhibition how important lighting is for art. The place of honour in Room VIII. is occupied by (402) Amaryllis, by George Harcourt, A.R.A. ; it is brilliant when the sun is shining outside, but Amaryllis in the shade loses-a good deal of its appeal. No.42, by James Durden, suggests a physical or physiological problem--why does a grey sky appear intensely blue when seen in the twilight from an interior?

Some artists apparently conceive it to be their duty to stimulate our artistic sense by notes of interrogation. No. 594, Stamford Brook, is no brook but a junction of railway lines; that question, however, is mainly verbal and easy ; but what " the Devil's Chess Board " means (275), Otway McCannell, or even what Past, Present, and Future $\left(3^{6} 7\right)$ is intended to convey, the visitor is left to make out for himself, and perhaps will have improved his sense of beauty when he knows.

\section{The Toronto Meeting of the British Association.}

\section{(From our Toronto Correspondent.)}

$\mathrm{T}^{\mathrm{H}}$ HE British Association, as has been announced already, will hold its ninety-second annual meeting in Toronto, Canada. The invitation was proffered by the University of Toronto and the Royal Canadian Institute, but the whole of scientific Canada is co-operating to ensure that the meeting shall be one of the most successful in the history of the Association, and that the visitors from overseas shall have an enjoyable and profitable experience. For several months past, committees and associate committees, under the general chairmanship of Prof. J. C. McLennan, have been working in co-operation with the central organisation in England, and the success of the meeting seems certain. The British Association is no stranger to Canada, its first overseas meeting having been held in Montreal in 1884 . It came again in 1897 and 1909 , the meeting-places being Toronto and Winnipeg.

The dates for the Toronto meeting this year are August 6-August I3, and almost coincident with the meeting of the Association an International Mathematical Congress will be held, also in Toronto, on August II-I6. Various Canadian educational and professional organisations have arranged to hold gatherings in Toronto during the same week. Entertainments, garden parties, receptions, and excursions have therefore been arranged to include both Association and Congress visitors.

Fortunately there will, in August, be ample accommodation available for the visitors in the homes of citizens, the many convenient hotels, clubs, college and university residences, and the fraternities contiguous to the grounds of the University where the meetings will take place.

The University of Toronto is the provincial University of Ontario, and is financed almost entirely by the Government of the Province. It was founded in 1827 , and has now a student body numbering about 5000 . It ranks, therefore, as one of the largest universities in the British Empire.

The University is formed by a federation of four colleges, and students from other affiliated colleges are registered for courses leading to degrees. It is one of the chief centres for graduate work in the Dominion, and students from all parts of Canada come to the University of Toronto for the purpose of working in advanced courses and research leading to its higher degrees.

The University is located centrally in the city, and its ample buildings and campus provide an ideal meetingplace for such a congress. The social side of the meetings is especially well provided for, and the visitors will find in Hart House, which is the social and recreational centre of the male University life, a building which has few equals in the world for the beauty of its interior architecture and its lavish provision of comfort and convenience. Adjoining Hart House is the beautiful tower erected as a war memorial by the alumni of the University.

Close to the University grounds are several institutions which will doubtless be of interest to the visitors. Among these are McMaster University, which is maintained by the Baptist Church; the Royal Canadian Institute, founded in 1849 and the oldest scientific body in Canada; the Royal Ontario Museum, directed by members of the University staff, and containing among its notable collections that illustrating the ethnology of the American Indians, Chinese art and pottery, and a magnificent collection of fossil deinosaurs; the Connaught Antitoxin Laboratory, one of four institutions of its kind in the British Empire, which among its many activities manufactures and distributes insulin; the Toronto General Hospital of $75^{\circ}$ beds; the Sick Children's Hospital, and the Provincial Parliament House, situated in Queen's Park, which is adjacent to the University grounds.

Toronto is situated in the southernmost part of the Dominion. It has an important harbour for the Great Lakes and St. Lawrence traffic, and it has direct railway connexions with all the important cities in Canada and the United States. One may, for example, leave Toronto by train at night and arrive in New York City shortly after breakfast next morning. Within a few hours of Toronto is the Muskoka lake district, one of the many great summer holiday resorts of the continent. For the information of those of the visiting scientific workers who may wish to recuperate after the strenuous exertions of the meeting, the steamship and railway

NO. 2848 , VOL. I I 3$]$ 